\title{
Stable disk assemblies of a tobacco mosaic virus mutant as nanoscale scaffolds for applications in drug delivery
}

\author{
Joel A. Finbloom, ${ }^{a}$ Kenneth Han, ${ }^{a}$ Ioana L. Aanei, ${ }^{a, b}$ Emily C. Hartman, ${ }^{\text {a,b }}$ Daniel T. Finley, ${ }^{a}$ \\ Michel T. Dedeo, ${ }^{\mathrm{a}}$ Max Fishman, ${ }^{\mathrm{a}}$ Kenneth H. Downing, ${ }^{\mathrm{c}}$ and Matthew B. Francis*a,b \\ ${ }^{a}$ Department of Chemistry, University of California, Berkeley. ${ }^{b}$ Materials Sciences Division, ${ }^{c}$ Life \\ Sciences Division, Lawrence Berkeley National Laboratory, Berkeley, California 94720 \\ *mbfrancis@berkeley.edu
}

\section{SUPPORTING INFORMATION}

\section{Table of Contents}

S1. General Methods $\quad$ S2

S2. Experimental Procedures $\quad$ S2

S3. Supplementary Figures $\quad$ S5

Figure S1. TEM of RR-TMV disks in NaPhos $\quad$ S5

Figure S2. TEM of RR-TMV disks in NaOAc S5

Figure S3. Cryo-EM of RR-TMV disks in NaPhos S6

Figure S4. Dynamic light scattering of RR-TMV S6

Figure S5. Modeling of wtTMV salt bridges $\quad$ S7

Figure S6. Modeling of RR-TMV salt bridges $\quad$ S8

Figure S7. AF488 modification of RR-TMV S9

Figure S8. SEC of AF488-maleimide $\quad$ S9

Figure S9. MS analysis of serum stability studies $\quad$ S10

Figure S10. Gel electrophoresis of TMV $\mathrm{TH}_{\mathrm{AF} 488-\mathrm{PEG}} \quad \mathrm{S} 10$

Figure S11. Stability of RR-TMV disks in PBS at $5 \mathrm{~d}$ S11

Figure S12. Oxidation of RR-TMV

Figure S13. Cell uptake of RR-TMV

Figure S14. Cell uptake of RR-TMV $\quad$ S12

$\begin{array}{ll}\text { S4. References } & \text { S13 }\end{array}$ 


\section{S1. General Methods}

All solvents and reagents, including doxorucibin-HCl, were purchased from commercial suppliers and used without further purification. DOX-EMCH was prepared according to literature procedures. ${ }^{\mathrm{S} 1}$ Thin layer chromatography (TLC) was performed on silica gel $60 \mathrm{~F}_{254}$ (E. Merck) and visualized under a UV lamp at $254 \mathrm{~nm}$. A C18 column was used for analytical and semi-preparative reverse phase high performance liquid chromatography (RP-HPLC) on an Agilent 1100 Series Capillary LC. Runs were eluted with $\mathrm{H}_{2} \mathrm{O} / \mathrm{MeCN}(0.1 \% \mathrm{v} / \mathrm{v}$ TFA) and monitored using a UV-Vis detector. Nuclear magnetic resonance (NMR) spectra were recorded on Bruker Avance 400 with working frequencies of $400 \mathrm{MHz}$ for ${ }^{1} \mathrm{H}$ NMR, and $100 \mathrm{MHz}$ for ${ }^{13} \mathrm{C}$ NMR, respectively. UV-Vis spectra were obtained using a NanoDrop (Thermo Scientific).

\section{S2. Experimental Procedures}

Protein expression and purification. The starting point for the RR-TMV protein was a gene for the coat protein of the TMV U1 strain optimized for the codon usage of $E$. coli (Genscript, Piscataway, NJ). Site-directed mutagenesis was performed using QuikChange mutagenesis (Stratagene, Santa Clara, CA). For N-terminal oxidative coupling, the $\mathrm{N}$ terminus of the RR-TMV was extended from SYS to PAGSYS using the primers:

sense: 5' - GAAGGAGATATACATATGCCTGCCGGCAGCTATAGCATTACC - 3' antisense: 5' - TGCTATAGCTGCCGGCAGGCATATGTATATCTCCTTCTTAAG - 3'

The RR-TMV coat protein was expressed to contain K53R, K68R, T104K, S123C, and PAGSYS N-terminal mutations. BL21 DE3 RIL Codon+ cells were transformed with the vector described above, and cultured in Terrific Broth with $100 \mu \mathrm{g} / \mathrm{L}$ ampicillin at $37{ }^{\circ} \mathrm{C}$. When cultures reached optical densities of 0.6 to 0.8 , IPTG was added to a final concentration of $30 \mu \mathrm{M}$. Cultures were grown $24 \mathrm{~h}$ at $30^{\circ} \mathrm{C}$, harvested by centrifugation, and stored at $-80^{\circ} \mathrm{C}$. Cells (from a $1 \mathrm{~L}$ expression batch) were thawed, resuspended in $20 \mathrm{~mL}$ of $20 \mathrm{mM}$ TEA pH 8 , and lysed by sonicating with a 2 $\mathrm{s}$ on, $4 \mathrm{~s}$ off cycle for a total of 30 min using a standard disruptor horn at $90 \%$ amplitude (Fischer Scientific). The resulting lysate was cleared by ultracentrifugation for $30 \mathrm{~min}$ at $45,000 \mathrm{rpm}$ using a Beckman 45 Ti rotor in an Optima L-80 XP (Beckman Coulter). The clarified lysate was decanted, warmed to room temperature, and stirred while adding a saturated solution of ammonium sulfate dropwise to a final concentration of $50 \%(\mathrm{v} / \mathrm{v})$. After $5 \mathrm{~min}$, the white ppt that formed was pelleted by ultracentrifugation ( $30 \mathrm{~min}$ at $45,000 \mathrm{rpm}$ in a Beckman 45 Ti rotor), and resuspended in $20 \mathrm{mM}$ TEA pH 7.2. The resulting protein solution was next loaded onto a diethylaminoethanol (DEAE) Sepharose column and eluted with a $0-300 \mathrm{mM} \mathrm{NaCl}$ gradient. Purity was confirmed by SDS-PAGE and HPLC. This preparation provided pure RR-TMV in yields up to $100 \mathrm{mg} / \mathrm{L}$ culture.

Size Exclusion Chromatography (SEC). Analytical size exclusion was performed on an Agilent 1100 series HPLC equiped with a PolySep-GFC-P 5000 column (Phenomenex, Torrance, CA), at a flow rate of $1 \mathrm{~mL} / \mathrm{min}$.

Transmission Electron Microscopy (TEM). Samples were prepared for TEM analysis by applying an analyte solution (approximately $0.2 \mathrm{mg} / \mathrm{mL}$ in RR-TMV protein) to carbon-coated copper grids for $2 \mathrm{~min}$, followed by triple rinsing with dd $-\mathrm{H}_{2} \mathrm{O}$. The grids were then exposed to a $1.6 \%$ aqueous 
solution of uranyl acetate for $2 \mathrm{~min}$ as a negative stain. Images were obtained at the Berkeley Electron Microscope Lab using a FEI Tecnai 12 transmission electron microscope with $120 \mathrm{kV}$ accelerating voltage.

Dynamic light scattering (DLS) and zeta potential studies. DLS and zeta potential measurements were obtained using a Malvern Instruments Zetasizer Nano ZS. Data plots and standard deviations were calculated from an average of three measurements, each of which consisted of 10 runs of 45 $\mathrm{s}$ each. Measurement data are presented as a number distribution.

Mass spectrometry. Protein bioconjugates were analyzed using an Agilent 1200 series liquid chromatograph (Agilent Technologies, USA) that was connected in-line with an Agilent 6224 Time-of Flight (TOF) LC/MS system equipped with a Turbospray ion source.

Gel Analyses. For protein analysis, sodium dodecyl sulfate-polyacrylamide gel electrophoresis (SDS-PAGE) was carried out on a Mini-Protean apparatus (Bio-Rad, Hercules, CA), using a 10$20 \%$ precast linear gradient polyacrylamide gel (Bio-Rad). All protein electrophoresis samples were heated for $5-10 \mathrm{~min}$ at $95{ }^{\circ} \mathrm{C}$ in the presence of 1,4-dithiothreitol (DTT) to ensure reduction of disulfide bonds. Gels were run for $75-90 \mathrm{~min}$ at $120 \mathrm{~V}$ to separate the bands. Commercially available markers (Bio-Rad) were applied to at least one lane of each gel for assignment of apparent molecular masses. Visualization of protein bands was accomplished by staining with Coomassie Brilliant Blue R-250 (Bio-Rad). ImageJ was used to determine the level of modification by optical densitometry.

General procedure for Alexa Fluor 488 conjugation to RR-TMV. To a solution of RR-TMV (PAGSYS N-terminus, S123C, T104K, $100 \mu \mathrm{M}$ ) in $10 \mathrm{mM} \mathrm{pH} 7 \mathrm{NaPhos}$ buffer, 1.5 equiv of AF488 $(22.6 \mu \mathrm{L}$ of $1 \mathrm{mM}$ stock solution) was added. The solution was incubated for $1 \mathrm{~h}$, protected from light at room temperature. The solution was then spin concentrated 3-5 times into $10 \mathrm{mM} \mathrm{pH}$ $7 \mathrm{NaPhos}$ buffer.

General procedure for aminophenol-PEG 5 conjugation to RR-TMV. To a solution of RR-TMV (PAGSYS N-terminus, S123C, T104K, $100 \mu \mathrm{M}$ ) in $20 \mathrm{mM} \mathrm{pH} 7.5 \mathrm{NaPhos}$ buffer, 2 equiv of $N$ ethyl maleimide $(0.8 \mu \mathrm{L}$ of a $100 \mathrm{mM}$ stock solution) was added. The reaction was incubated for $1 \mathrm{~h}$ at room temperature. An aliquot of the mixture was analyzed by ESI-TOF MS to confirm the

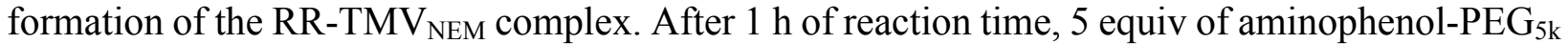
(133 $\mu \mathrm{L}$ of $3 \mathrm{mM}$ stock solution) was added. Following this, 50 equiv of $\mathrm{K}_{3} \mathrm{Fe}(\mathrm{CN})_{6}(80 \mu \mathrm{L}$ of a 3 $\mathrm{mM}$ stock solution) was added. After $30 \mathrm{~min}$ of incubation at room temperature, the solution was spin concentrated 3-5 times into $10 \mathrm{mM} \mathrm{pH} 7 \mathrm{NaPhos}$ buffer with a 30k molecular weight cutoff (MWCO) spin concentrator (Millipore).

General procedure for maleimide-PEG $G_{5 k}$ conjugation to RR-TMV. To a solution of RR-TMV

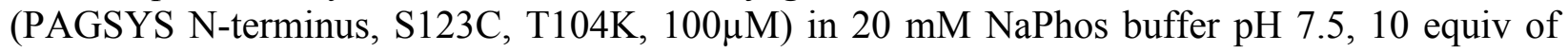
maleimide- $\mathrm{PEG}_{5 \mathrm{k}}(8 \mu \mathrm{L}$ of $50 \mathrm{mM}$ stock solution) was added. After $2 \mathrm{~h}$ of incubation at room temperature, the solution was spin concentrated 3-5 times into $10 \mathrm{mM} \mathrm{NaPhos}$ buffer $\mathrm{pH} 7$ with a 30k MWCO spin concentrator. 
General procedure for doxorubicin and aminophenol-PEG $G_{5 k}$ conjugation to RR-TMV. To a solution of RR-TMV (PAGSYS N-terminus, S123C, T104K, $100 \mu \mathrm{M}$ ) in $20 \mathrm{mM}$ pH $7.5 \mathrm{NaPhos}$ buffer, 1 equiv of DOX-EMCH ( $2 \mu \mathrm{L}$ of a $100 \mathrm{mM}$ stock solution in DMSO) was added. The solution was incubated for $1 \mathrm{~h}$, protected from light at room temperature. An aliquot of the mixture was analyzed by ESI-TOF MS to confirm the formation of the RR-TMV Dox complex. Then, 5 equiv of $\mathrm{PEG}_{5 \mathrm{k}}$-aminophenol $(400 \mu \mathrm{L}$ of a $2.5 \mathrm{mM}$ stock) was added to the solution. Following this, 50 equiv of $\mathrm{K}_{3} \mathrm{Fe}(\mathrm{CN})_{6}$, $(200 \mu \mathrm{L}$ of a $50 \mathrm{mM}$ stock solution) was added. After 30 min of incubation at room temperature, the solution was spin concentrated 3-5 times into PBS with a $30 \mathrm{k}$ MWCO spin concentrator.

Cell culture. U87MG human glioblastoma cells were obtained from the UC Berkeley Cell Culture Facility. Cells were cultured in DMEM containing phenol red (ATCC, Manassas, VA) or DMEM without phenol red (Thermo, Waltham, MA) with 10\% fetal bovine serum (Omega Scientific, Tarzana, CA) and $1 \%$ penicillin/streptomycin (Thermo) at $37{ }^{\circ} \mathrm{C}$ and $5 \% \mathrm{CO}_{2}$.

MTS cell viability assay. A 3-(4,5-Dimethylthiazol-2-yl)-5-(3-carboxymethoxyphenyl)-2-(4sulfophenyl)-2H-tetrazolium (MTS) cell viability assay was purchased from Promega and used according to the manufacturer's instructions. U87MG cells were cultured in high glucose DMEM containing $10 \%$ fetal bovine serum and penicillin and streptomycin. Cells were plated in 96-well microtiter plates at 5000 cells per well and incubated overnight to allow adhesion. After overnight incubation, the media was removed and exchanged with either DOX, RR-TMV, or RR-TMV $V_{\text {DOX- }}$ PEG stock solutions prepared in cell media at the appropriate concentration. Cell viability was measured after $72 \mathrm{~h}$ using an MTS cell viability assay and was used according to the supplier's instructions. The cell media was replaced after $72 \mathrm{~h}$ with a stock of $20 \%$ MTS solution in cell media. The plate was incubated for 1-3 $\mathrm{h}$, and the absorbance was read using a microplate reader (490 nm). Cell viability was calculated as an absorbance percent relative to the untreated cell control. Cells were treated in triplicate.

Cell uptake studies. U87MG cells were seeded in a 96 well plate as $200 \mu \mathrm{L}$ solutions of 50,000 cells $/ \mathrm{mL}$. The cells were allowed to grow and adhere to the plate for $48 \mathrm{~h}$ in DMEM media with $10 \% \mathrm{FBS}$ and $1 \% \mathrm{P} / \mathrm{S}$ at $37{ }^{\circ} \mathrm{C}$ and $5 \% \mathrm{CO}_{2}$. The media was removed and replaced with $200 \mu \mathrm{L}$ DMEM without phenol red containing RR-TMV $V_{\text {DOX-PEG }}$ conjugates at a final concentration of 1 $\mu \mathrm{M}$ DOX (3 $\mu \mathrm{M}$ RR-TMV coat protein) or $2 \mu \mathrm{M}$ unmodified RR-TMV coat protein. The cells were incubated with the agents for an additional $48 \mathrm{~h}$. Incucyte Zoom Live-Cell Analysis System (EssenBio, Ann Arbor, MI) was used to collect images every hour post incubation. Phase and green fluorescence images at 20x magnification were collected, capitalizing on the intrinsic fluorescence of doxorubicin. The images were processed using Incucyte Zoom proprietary software v.2016A, and the Top-Hat background subtraction algorithm (radius $10 \mu \mathrm{m}$, threshold $0.5 \%$ of green calibration dye signal, GCU) was used to define the boundaries of the cells (green objects). The mean green object fluorescence intensities of 4 images taken in each well were plotted against the incubation time. 


\section{S3. Supplementary figures}

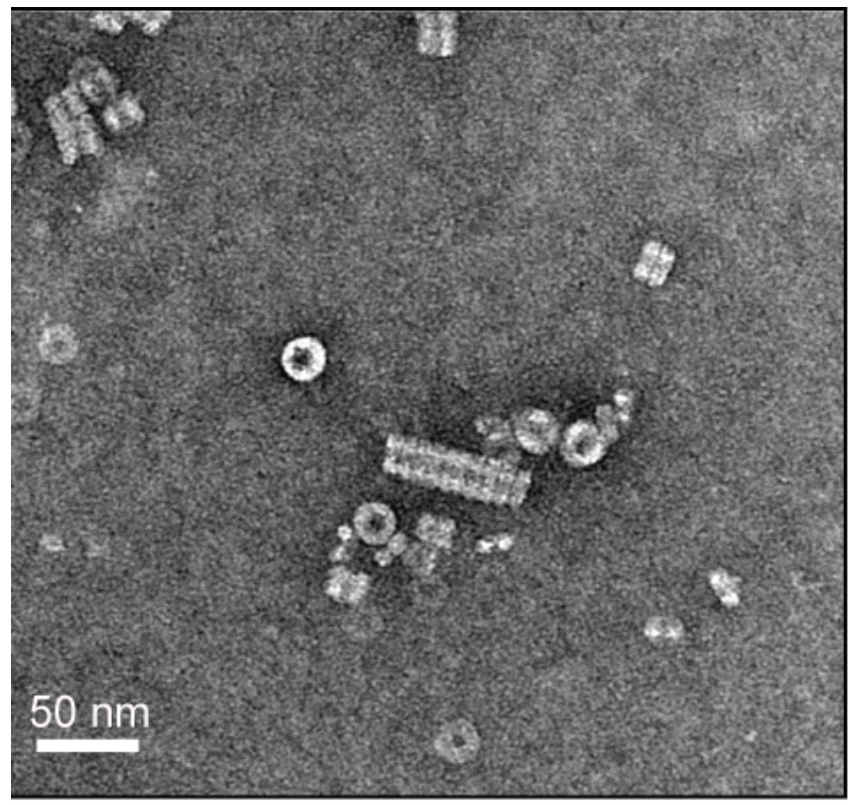

$10 \mathrm{mM}$ NaPhos $\mathrm{pH} 7.0$

Figure S1. Transmission electron microscopy of RR-TMV disks in $10 \mathrm{mM} \mathrm{pH} \mathrm{7.0} \mathrm{NaPhos}$ buffer.

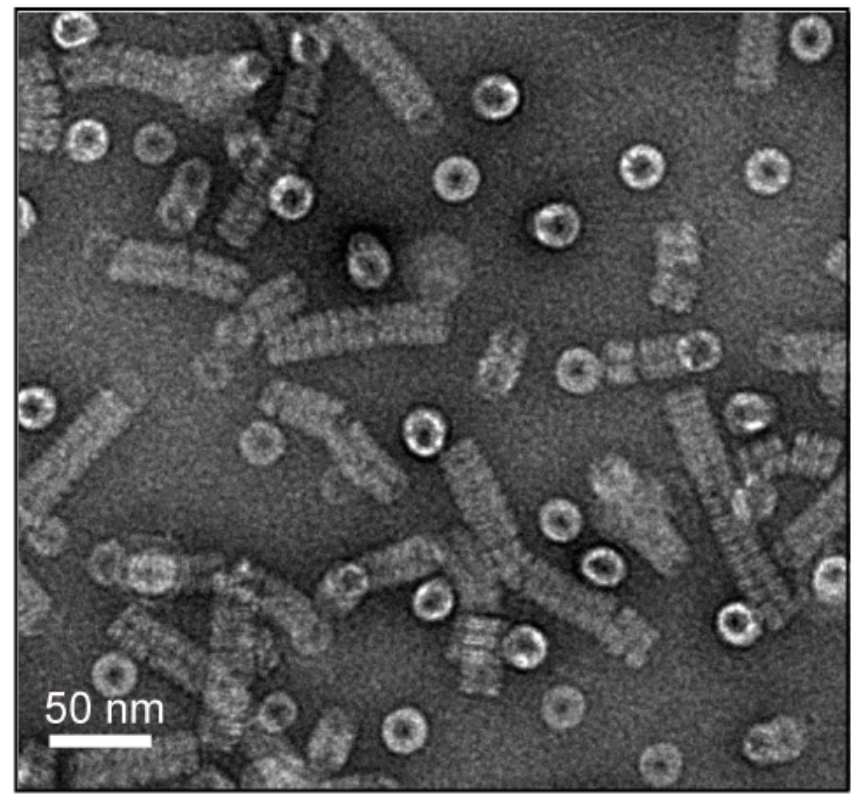

$50 \mathrm{mM} \mathrm{NaOAc}$ pH 5.5

Figure S2. Transmission electron microscopy of RR-TMV disks in $50 \mathrm{mM} \mathrm{pH} 7.0 \mathrm{NaOAc}$ buffer. 


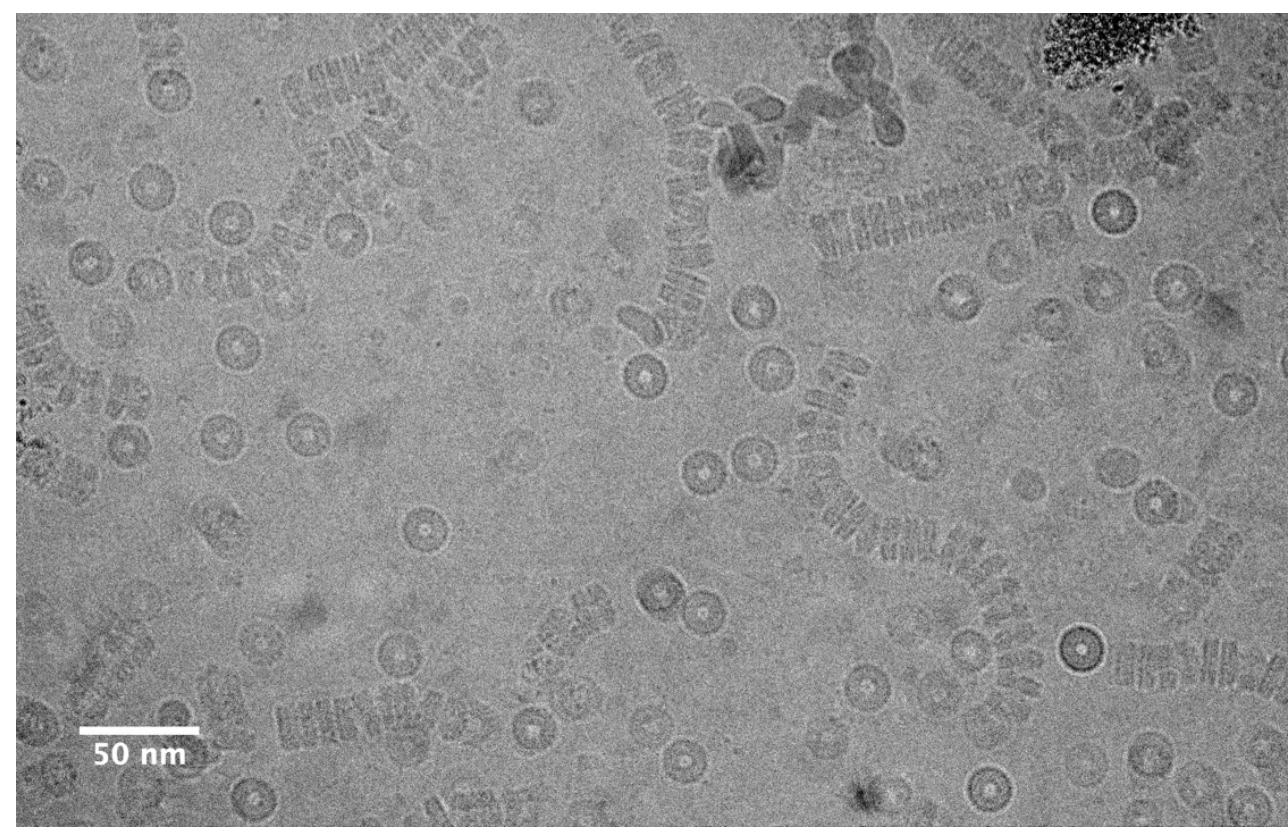

Figure S3. Cryogenic transmission electron microscopy of RR-TMV disks in $10 \mathrm{mM}$ pH 7.0 NaPhos buffer.

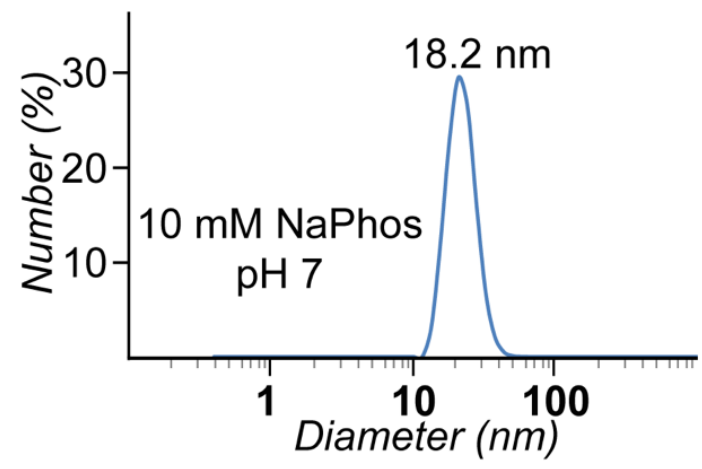

Figure S4. Dynamic light scattering (DLS) indicated a $18.2 \mathrm{~nm}$ diameter of RR-TMV disks. 

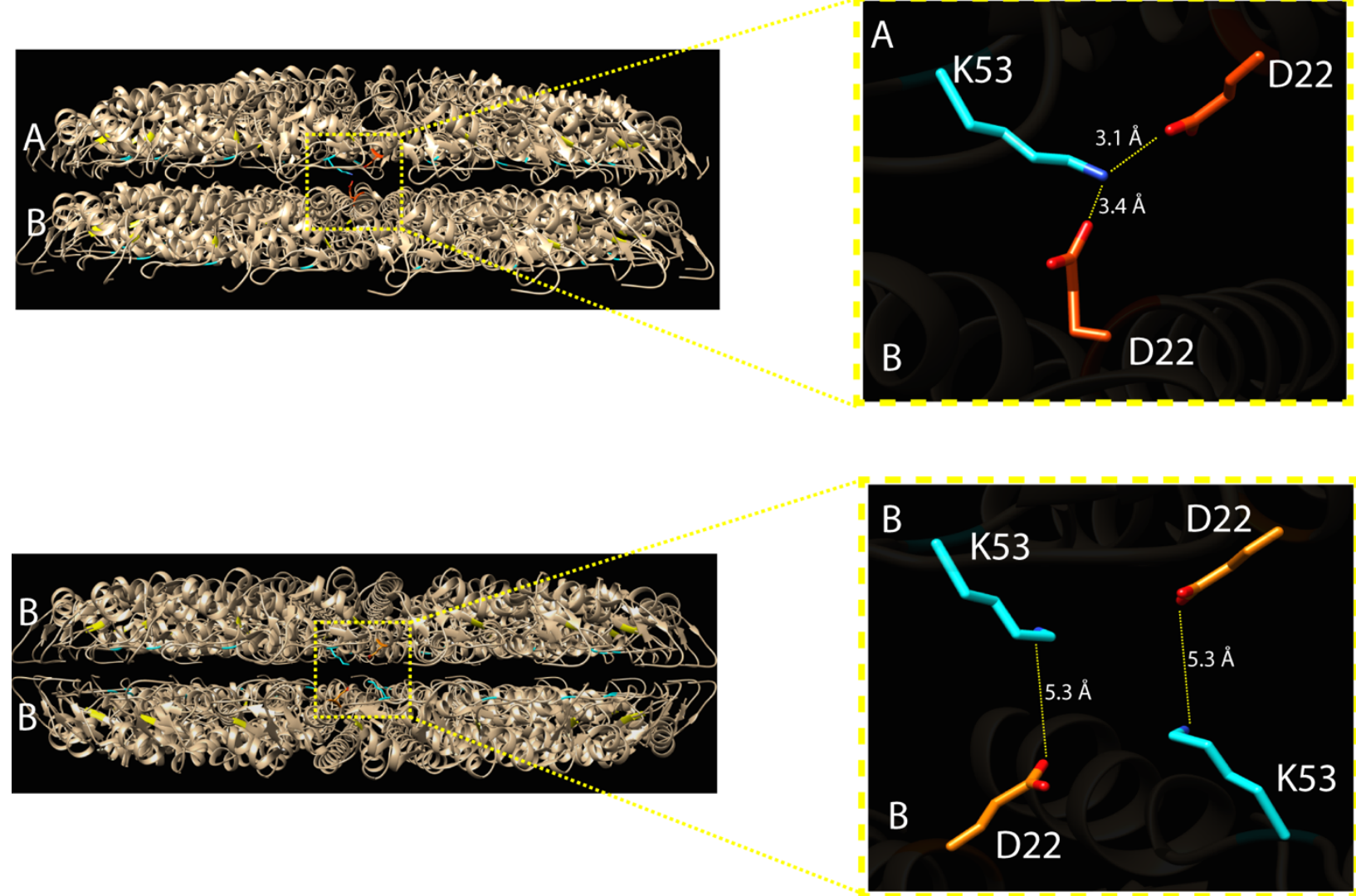

Figure S5. Modeling of wtTMV salt bridges. UCSF Chimera ${ }^{\mathrm{S} 2}$ was used to determine any natural salt bridges present in wtTMV at position K53. AB disk stacking revealed potential salt bridges, while $\mathrm{BB}$ stacking did not contain any salt bridges within the literature reported salt bridge distance of 4 A. ${ }^{\mathrm{S} 3}$ PDB file 1EI7 (wtTMV) was used for modelling. No salt bridges were observed at K68. 



Figure S6. Modeling of RR-TMV salt bridges. UCSF Chimera ${ }^{\mathrm{S} 2}$ was used to determine any salt bridges present in RR-TMV at position K53R. AB and BB disk stacking revealed potential salt bridges in accordance with the literature reported salt bridge distance of $4 \AA$. 33 PDB file 1 EI7 (wtTMV) mutated with K53R and K68R was used for modelling. No salt bridges were observed at K68R. 


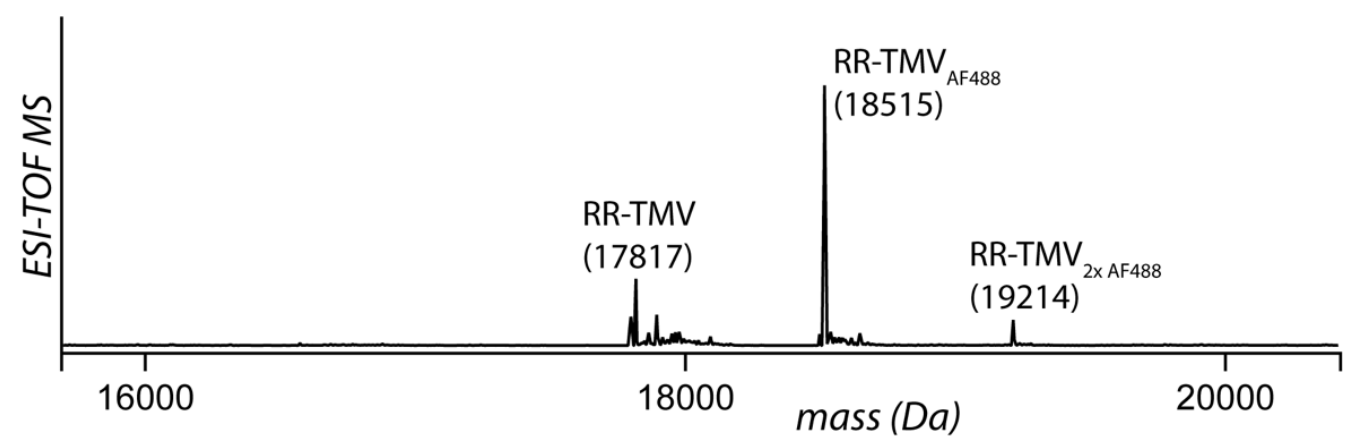

Figure S7. AF488 modification of RR-TMV. RR-TMV (expected mass of 17817 Da) was modified with AF488-maleimide (18515 Da). A slight second addition of AF488 (19214 Da) was also observed.

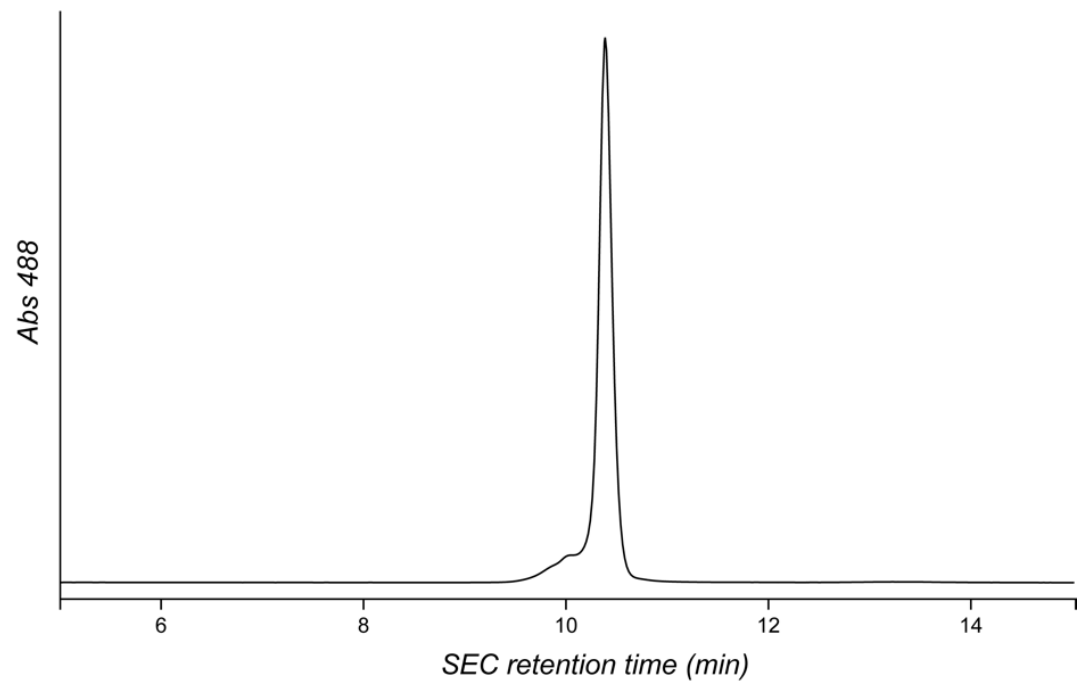

Figure S8. SEC analysis of AF488-maleimide. An HPLC-SEC analysis of AF488-maleimide revealed a retention time of $\sim 10.2 \mathrm{~min}$. 

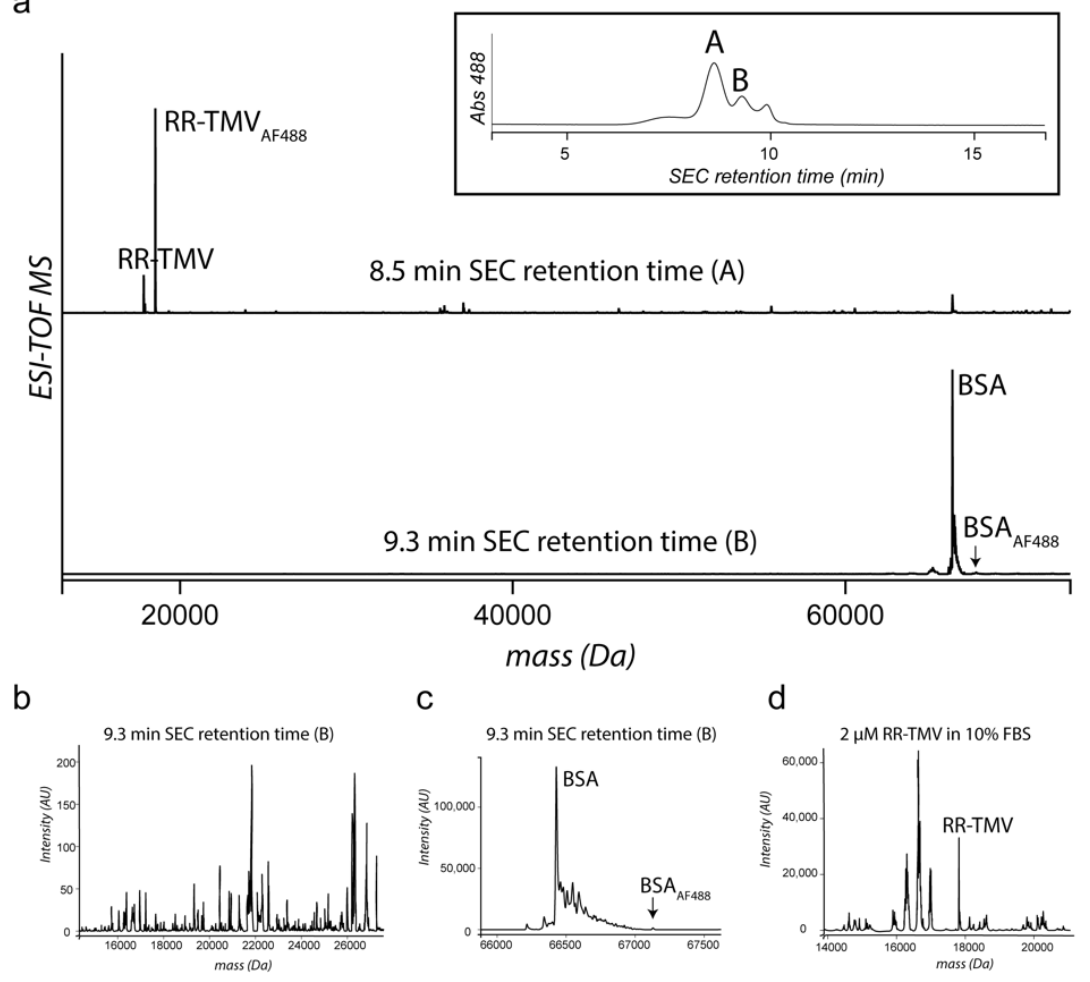

Figure S9. ESI-TOF MS analysis of serum stability samples. (a) Fractions at 8.5 and 9.3 min SEC retention times were collected and subjected to ESI-TOF MS analysis. RR-TMV and RR$\mathrm{TMV}_{\mathrm{AF} 488}$ were observed in the $8.5 \mathrm{~min}$ fraction (A). Small traces of BSA were also observed. In the 9.3 min fraction (B), only BSA was observed, with a very small BSA $\mathrm{AF}_{488}$ peak at $67130 \mathrm{Da}$. No RR-TMV was observed in the 9.3 min fraction. (b) Zoomed-in analysis of TMV MS range for the 9.3 min fraction. No MS peak corresponding to RR-TMV was observed, even in the noise intensity range. (c) Zoomed-in analysis of BSA MS range for the 9.3 min fraction. A small peak corresponding to $\mathrm{BSA}_{\mathrm{AF} 488}(67130 \mathrm{Da})$ was observed with a 1500 intensity (AU). (d) RR-TMV $(2 \mu \mathrm{M})$ was incubated in $10 \%$ FBS to determine if lower concentrations of RR-TMV could be detected by MS in the presence of serum. A small but detectable peak corresponding to the mass of RR-TMV was observed. No such peak was observed in the 9.3 minute SEC fraction.

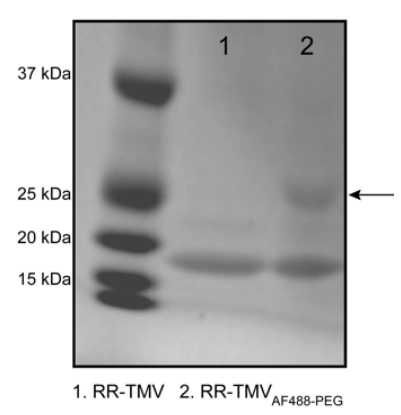

Figure S10. Gel electrophoresis analysis of $\mathrm{TMV}_{\mathrm{AF} 488-\mathrm{PEG}}$. RR-TMV $\mathrm{AF}_{\mathrm{A} 48}$ was PEGylated at the N-terminus with aminophenol-PEG $5 \mathrm{k}$. Approximately 30\% PEGylation was observed. 


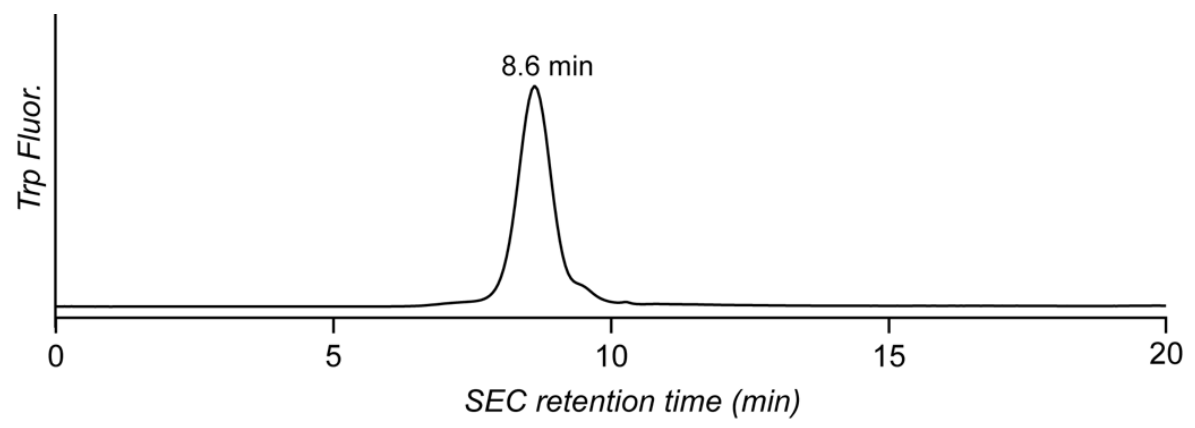

Figure S11. Stability of RR-TMV disks in PBS after $5 \mathrm{~d}$. RR-TMV was incubated at $37^{\circ} \mathrm{C}$ for 5 $\mathrm{d}$ and analyzed by HPLC-SEC. Disks were the only assembly state observed.
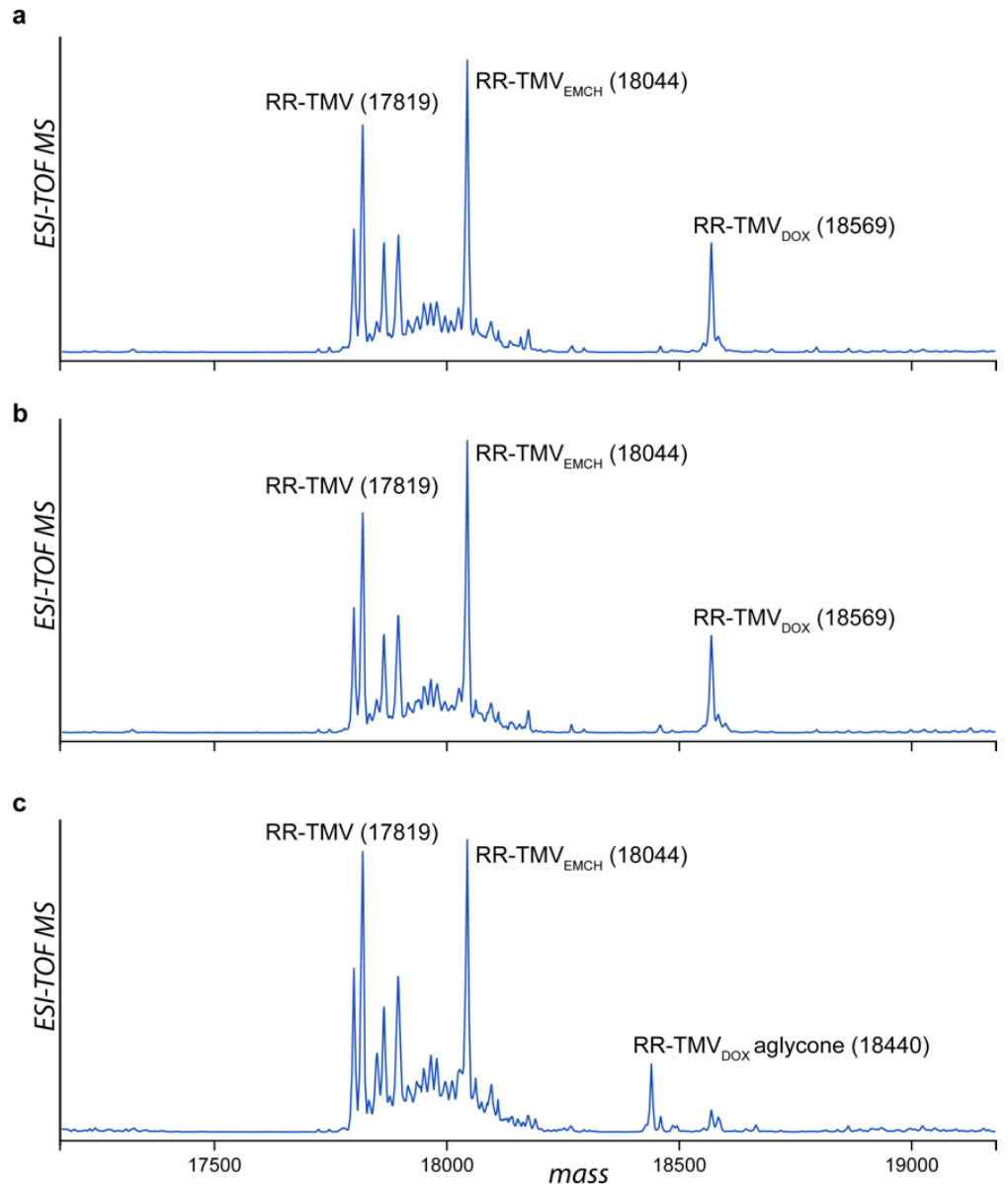

Figure S12. Treatment of RR-TMV $\mathrm{DOX}_{\text {with }} \mathrm{NaIO}_{4}$ and $\mathrm{K}_{3} \mathrm{Fe}(\mathrm{CN})_{6}$. (a) ESI-TOF mass spectrum of RR-TMV $V_{\text {DOX }}$. The RR-TMV $\mathrm{EMCH}_{\text {EM }}$ peak is likely due to DOX release in the $0.1 \%$ formic acid mobile phase. Additional peaks were observed at 17865 and $17895 \mathrm{Da}$. (b) Treatment with $\mathrm{K}_{3} \mathrm{Fe}(\mathrm{CN})_{6}$ did not cause any observable mass changes by ESI-TOF MS analysis. (c) Treatment with $\mathrm{NaIO}_{4}$ caused a mass loss of $129 \mathrm{Da}$, corresponding with the glycolysis of doxorubicin. 


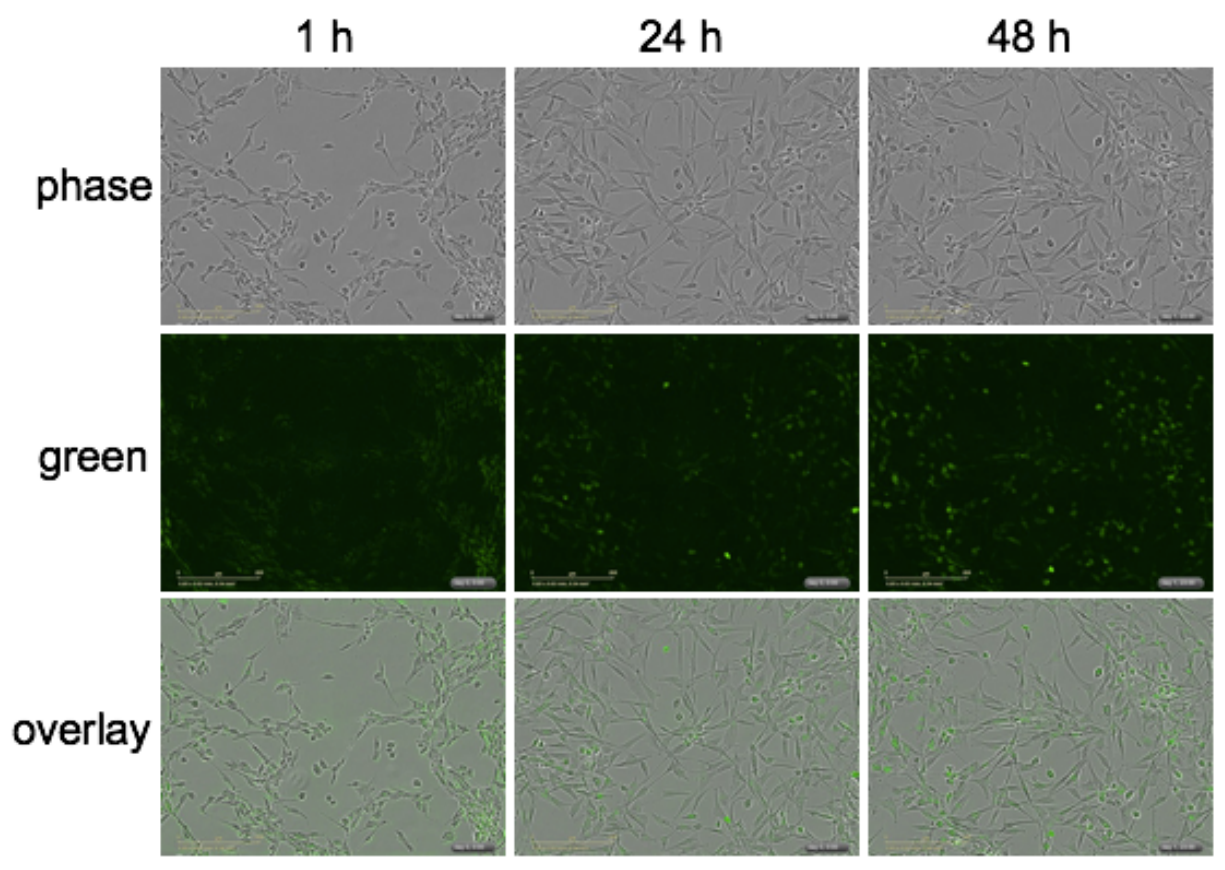

Figure S12. Cell uptake of RR-TMV $\mathrm{DOX}_{\text {-PEG }}$ Fluorescence microscopy images of U87MG cells incubated with RR-TMV $\mathrm{DOX}_{\text {PEG }}$ at 1,24 , and $48 \mathrm{~h}$ incubation times.

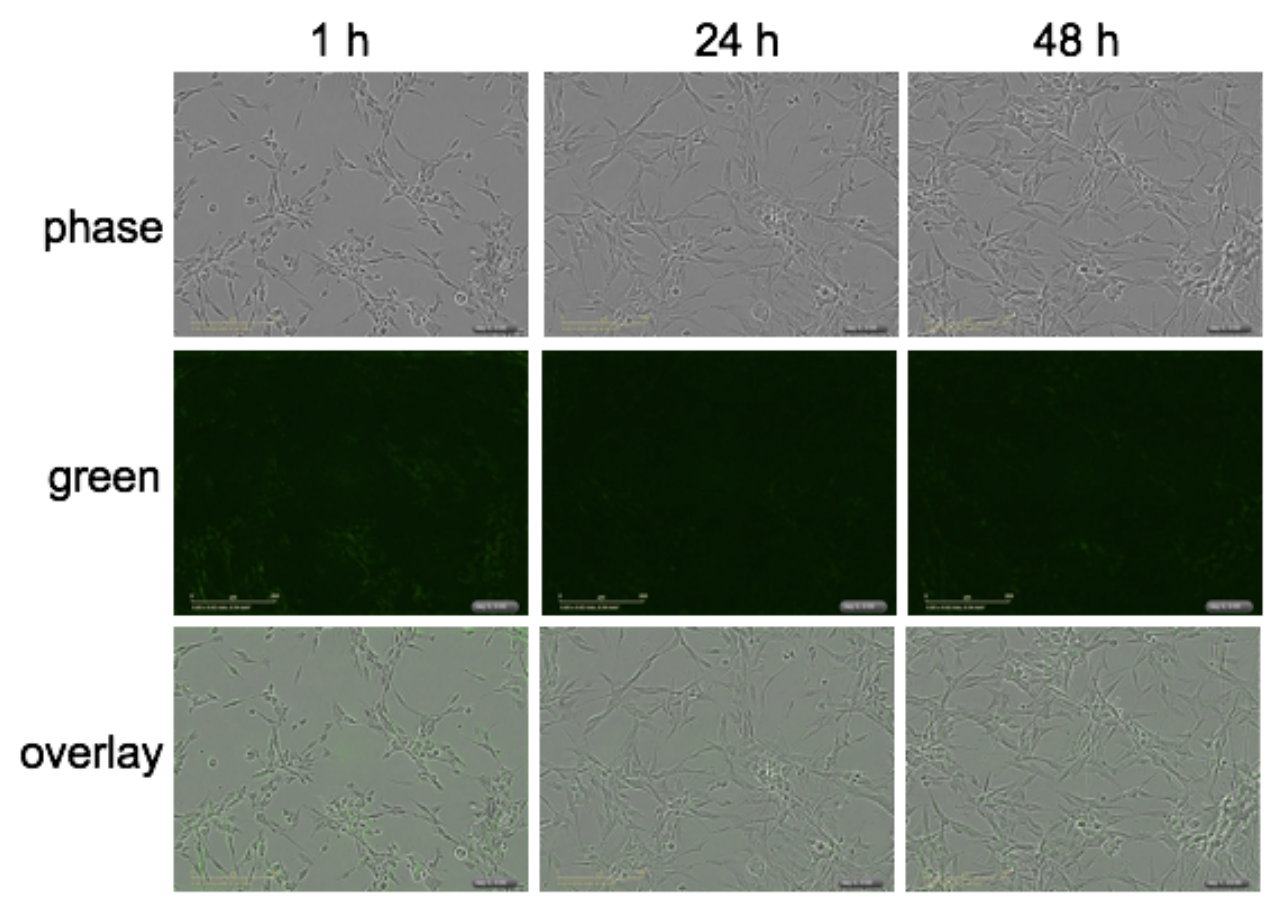

Figures S13. Cell uptake of RR-TMV to check for background fluorescence and confirm normal cell morphology. Fluorescence microscopy images of U87MG cells incubated with RR-TMV at 1,24 , and $48 \mathrm{~h}$ incubation times. 


\section{S4. References}

S1. Toita, R., Murata, M., Abe, K., Narahara, S., Piao, J. S., Kang, J. H., and Hashizume, M. (2013) A nanocarrier based on a genetically engineered protein cage to deliver doxorubicin to human hepatocellular carcinoma cells. Chem. Commun. 49, 7442-7444.

S2. Petterson, E. F., Goddard, T. D., Huang, C. C., Couch, G. S., Greenblatt, D. M., Meng, E. C., and Ferrin, T. E. (2004) UCSF chimera. J. Comput. Chem. 25, 1605-1612.

S3. Kumar, S., and Nussinov, R. (2002) Close-range electrostatic interactions in proteins. ChemBioChem. 3, 604-617. 